\title{
An Analysis of Factors Influencing Individually- and Socially Oriented Happiness: The Case of Seoul
}

\author{
Miruh Jeon,* Minhyung Shin*** and Seung Jong Lee***
}

\begin{abstract}
This paper compares factors that influence individually oriented and socially oriented happiness. Going beyond simply identifying and analyzing factors that affect happiness, we explore how two sets of determinants, demographic factors and environmental factors, influence these two different types of happiness. We hypothesize that demographic factors and environmental factors will impact individually oriented and socially oriented happiness differently, and we empirically test it employing the 2012 Seoul Survey data. The analytical results supported the hypothesis: demographic factors such as education, employment status, and marital status are more strongly associated with individually oriented happiness; and environmental factors such as environment, group participation, individual participation, leisure activities are more strongly associated with socially oriented happiness. Our research findings reveal that the approach that most studies of determinants of happiness have taken is limited in that it presupposes happiness as a unidimensional concept.
\end{abstract}

Keywords: individually oriented happiness, socially oriented happiness, influence factors

\section{INTRODUCTION}

The issue of citizens' well-being and quality of life poses a major concern for most contemporary nations, including developed countries that have already achieved rela-

\footnotetext{
* Miruh Jeon is a master's candidate at the Graduate School of Public Administration at Seoul National University. E-mail: miruhljeon@snu.ac.kr.

** Minhyung Shin is a master's candidate at the Graduate School of Public Administration at Seoul National University. E-mail: rtshin24@snu.ac.kr.

*** Seung Jong Lee is the corresponding author and a professor at the Graduate School of Public Administration at Seoul National University. E-mail: slee@snu.ac.kr.

Manuscript received Jun 20, 2014; out for review Jun 30, 2014; review completed July 26, 2014; accepted July 28, 2014.
}

The Korean Journal of Policy Studies, Vol. 29, No. 2 (2014), pp. 43-69.

(C) 2014 by the GSPA, Seoul National University 
tively high levels of scientific and economic development (Economist, 2010). Nations have established legislative objectives aimed at ensuring happier lives for their citizens (Choi, 2011), thereby creating a continuous demand for research on the subject of happiness. Assuming that the ultimate goal of public administration and policy making is to increase citizens' happiness, research in this area is imperative.

A wealth of happiness literature covers a variety of factors that influence happiness, from general factors (e.g., individual characteristics, demographic factors) to specific ones (e.g., political, social, environmental factors). Previous studies have focused on searching for happiness indicators and examining the correlation between those indicators and happiness, with the ultimate goal of providing valuable and practical conclusions that can guide the making of policy and its implementation as well as future research (Argyle, 1999; Ryan \& Deci, 2001; Yang, Hsee, \& Zheng, 2012). In general, the literature on happiness tends to focus broadly on an overarching concept of happiness. In contrast, we distinguish between two types of happiness: individually oriented and socially oriented happiness. While previous studies have been able to verify specific factors that influence happiness, they have not always been successful in examining the differentiated effects of such factors on the two types of happiness. What sets our research apart is that we distinguish between individual and social factors and analyze their impacts on each type of happiness. We conceptualize individual happiness as a feeling that one has based on self-judgment of one's circumstances, such as financial status and health, and social happiness as an emotion one feels as a result of one's relationships with society's various types of constituents, including family, friends, and acquaintances.

The main purpose of this research is thus to conduct an analysis of the effects that two sets of influence factors (demographic factors and environmental factors) have on the two levels of happiness. While previous studies on individually- and socially oriented happiness have tended to focus on the prevailing type of happiness that exists within a culture (Feather, 1986; Markus \& Kitayama, 1991; Ahuvia, 2002; Lu \& Gilmour, 2004), we take this a step further and examine the relationship between the two types of happiness within one region.

Legislators must seek to formulate and execute policies designed to increase not only citizens' individual happiness but also their social happiness, which can be achieved by building and sustaining relationships among citizens within communities. Socially oriented happiness contributes to community as well as national development and, ultimately, promotes citizens' individual happiness (Veenhoven, 1993). Hence, the distinction between and the examination of individual and social happiness may have noteworthy implications in terms of policy making; in particular, during the policy- 
making process, legislators can take a more detailed look into which policies facilitate community development and cultivate a sense of community.

\section{CONCEPTUAL FRAMEWORK}

Despite the familiarity of the word, "happiness" is an ambiguous and complex term. In everyday usage, happiness is understood to be a feeling that connotes a sense of enjoyment and satisfaction - a pleasant emotional experience (Diener, 1984). However, studies of happiness reveal the intricacies and controversies surrounding its conceptualization (Leyden, Goldberg, \& Michelback, 2011; Duncan, 2008). Before moving on to define individually oriented happiness and socially oriented happiness, we offer a more general account of happiness.

\section{Conceptualization of Happiness}

The psychological literature points to two basic theories of happiness. The Greek philosopher Aristippus endorsed a hedonic view of happiness; that is, the "goal of life is to experience the maximum amount of pleasure, and that happiness is the totality of one's hedonic moments" (Ryan \& Deci, 2001, p. 143-144). Hedonism emphasizes following one's desires and avoiding pain to achieve happiness. Telic theories are related to hedonism in that they argue that "satisfaction of needs causes happiness and conversely, the persistence of unfulfilled needs causes unhappiness" (Diener, 1984, p. 562). However, scholars argue over whether fulfillment or suppression of desires leads to happiness, for some desires may actually be harmful. Unlike Aristippus, Aristotle denounced hedonism, for he saw it as an ideal that led humans to become "slavish followers of desires" (Ryan \& Deci, 2001, p. 145). Instead, he promoted eudemonism, which maintains that only by pursuing virtue can one achieve genuine happiness (Ryan \& Deci, 2001). Eudemonism urges individuals to live a purposeful life by realizing one's full potential; in short, this Aristotelian approach to happiness underscores the importance of one's daimon - one's true self (Waterman, Schwartz, \& Conti, 2008).

Veenhoven defines happiness as "the degree to which an individual judges the overall quality of his own life as a whole favorably" (2007, p. 2). The use of the terms "individual" and "judges" conveys that happiness is a subjective feeling (Veenhoven, 2007). Diener refers to three categories of definitions of happiness and subjective well-being: a state judged in terms of a value framework based on normative standards (e.g., virtue, holiness); a state viewed in terms of life satisfaction, grounded in subjective standards of what constitutes a good life; and a pleasant emotional experience 
characterized by a "preponderance of positive affect over negative affect" (1984, p. 543). Jeremy Bentham drew on utilitarianism in proposing his definition of happiness. He described happiness in terms of the hedonic view, that is, as a subjective feeling that is "the sum of pleasures and pains" (Veenhoven, 2007, p.2). Bradburn and associates at the National Opinion Research Center conceptualize happiness as "a function of the relation between the two independent dimensions of positive and negative affects," which are distinct and independent (Phillips, 1967, p. 479).

Drawing from findings of various studies of happiness, we have conceptualized happiness as an individual's subjective state in which he or she experiences more positive than negative affects. In essence, happiness is more than just a "simple sum of pleasures;" it is a cognitive construction that results from a person's review and assessment of his or her past, present, and future experiences (Diener, 1984). This is related to the measurement aspect of happiness as well as the subjective facet of happiness.

\section{Individually Oriented Happiness}

Under the broad umbrella of happiness, two subsets of happiness exist: individually oriented and socially oriented happiness. We argue that both types of happiness exist concurrently within any given culture, although one type may be more predominant.

Individually oriented happiness highlights the uniqueness of individuals and is based on the belief that self-representation comes from within the individual ( $\mathrm{Lu}$ and Gilmour, 2004, p. 274). According to Markus and Kitayama's (1991) depiction of the "independent construal of the self" (p. 226), individuals strive to distinguish themselves from others and appeal to internal attributes, abilities, and feelings to do so. Thus, selfrepresentations rely mostly on inner traits and capabilities, rather than on social relations and external contexts. Individually oriented happiness stresses the importance of being accountable for one's own happiness; the achievement of personal happiness, the pursuit of which is seen as an inalienable right, is recognized as a great accomplishment (Lu and Gilmour, 2004). This bespeaks view of personhood as "a bounded, unique, more or less integrated motivational and cognitive universe, a dynamic center of awareness, emotion, judgment, and action organized into a distinctive whole and set contrastively both against other such wholes and against a social and natural background" (Geertz, 1975, p. 48).

This type of individually oriented view is founded on the belief that the self is independent of and separate from others; the self is seen as "the wholeness and separateness of each individual's configuration of internal attributes" (Lu, Kao, Chang, Wu, \& Jin, 2008, p. 339). This type of perspective prevails in an individualistic society, which prioritizes free will and individual reason (Lu and Gilmour, 2004; Markus and 
Kitayama, 1998). The core concerns, issues, and values of individually oriented happiness deal with inner attributes, personal needs, personal achievement, and individual uniqueness. This type of happiness is perceived to be a function of what in psychology is called primary control (whereby one tries to master one's environment) and is achieved by proactively seeking to satisfy individual goals (Lu \& Gilmour, 2004, p. 277).

\section{Socially Oriented Happiness}

Socially oriented happiness is closely related to individuals' satisfaction with external factors within their environment. It can be described as a collective type of happiness in which individuals feel fulfilled through and take pleasure in relationships with other members of a society. This type of happiness is closely associated with what Markus and Kitayama refer to as the "interdependent construal of the self" (1991, p. 227) wherein the "self-in-relation-to-other" is the central focus of people's experiences (1991, p.225).

This type of collective-oriented happiness emphasizes societal harmony and relationships with others (Lu \& Gilmour, 2006). As Kondo explains, cultures that prioritize collective happiness stress the "fundamental connectedness of human beings to each other" (1990, p.9). Hence, a socially oriented conception of happiness underlines fitting in within a community and fulfilling social obligations, as well as establishing and sustaining interpersonal relationships (Markus \& Kitayama, 1991). Moreover, the quality and livability of an environment (safety, availability of parks, etc.) is an important determinant of socially oriented happiness (Veenhoven, 2007).

Furthermore, in terms of collectivism, a socially oriented form of happiness values a "relational way of being" (Lu \& Gilmour, 2004, p. 275; Markus and Kitayama, 1998). In other words, unlike individually oriented happiness, which prioritizes personal achievement and unique self-representation, a socially oriented conception of happiness understands individuals to achieve happiness by performing the roles expected of them within society, exercising self-control, and partaking in collective welfare (Lu \& Gilmour, 2004; Markus \& Kitayama, 1998). For example, "improving the livability of institutional settings such as schools, work organizations and old age homes can increase happiness" (Veenhoven, 2007, p. 2). In this case, enhancing the happiness of the society is considered more important — and thus is seen as a bigger factor in determining overall happiness - than promoting personal well-being (Veenhoven, 2007). Socially oriented happiness is considered to be a function of secondary control; it is achieved by immersing oneself within the environment and achieving harmony (Lu \& Gilmour, 2004). 


\section{Factors of Happiness}

The literature on happiness has yielded an abundance of variables that influence people's happiness: gender, age, marital status, income, religion, level of trust one has in others, emotional factors, and so on (Argyle, 1999). For simplicity, we divide the determinants of happiness into two categories: demographic factors and environmental factors. The main criterion used to distinguish between the types of determinants is whether the factors are individually or socially oriented. Demographic factors, which reveal personal information about a population, are considered individually oriented determinants; environmental factors, which involve external influences, are categorized as socially oriented determinants. We hypothesize that the two types of determinants will have different effects on people's individually oriented and socially oriented happiness.

We define demographic factors as personal facts about individuals that are perceived to be relatively free from the influences of one's connections with other members of society. Specifically, these factors are correlates of happiness that exclusively have to do with the individuals themselves rather than being attributes conferred through relationships with members of society. Accordingly, demographic factors feature in this research as individually oriented determinants of happiness.

A wealth of studies has found correlations between demographic variables and happiness (Argyle, 1999). The demographic variables of focus in this research include gender, age, education level, marital status, religion, income, occupation, and residence. These factors are related to attributes, traits, and abilities that form the core of an independent view of the self (Markus \& Kitayama, 1991). In particular, they are variables that disclose factual information (e.g., age, gender, income) or status (e.g., marital status, education level) of individuals. While we do not deny that an individual's society has an effect on these correlates of happiness - with the exclusion of gender and age-we nevertheless classify them as individually oriented determinants of happiness because the survey questions for these factors are designed in such a way as to elicit objective answers (e.g., the survey asks what one's income is rather than what one's social class is).

Environmental factors provide information about individuals' evaluations of their satisfaction with various aspects of their society and, thus, are socially oriented determinants of happiness. While we hypothesize that these factors will affect both a person's individual-level and collective-level happiness, these factors are expected to have a more notable role in shaping socially oriented happiness. Environmental determinants of happiness in our research include the forms of transportation available to individuals, their perception of the level of urban safety, the degree of trust individuals have in others, 
the extent of individuals' participation in individual and group activities, the quality of the living environment, individuals' satisfaction with available cultural activities and facilities, and the leisure activities an individual takes part in. Environmental factors are grounded in the ideals of the interdependent construal of the self. Hence, a focus on these correlates produces self-representations that emphasize the "self-in-relationto-others" within a society (Markus \& Kitayama, 1991).

Environmental determinants of happiness are correlated with what Yang et al. refer to as "relative determinants of happiness" that are "inherently inevaluable" (2012, p. 729). That is to say, using the level of trust an individual has in others as an example, an individual may not be able to gauge how much trust he or she has in others without external reference information from other members of his or her society.

The socially oriented self is characterized by a desire to meet socially approved goals or fulfill social obligations. In the context of this construal of the self, socially oriented goals and needs are ranked above individual needs and wants, and people who see themselves this way tend to seek to achieve externally defined goals ( $\mathrm{Lu}$ and Gilmour, 2004). Accordingly, factors that are closely correlated with this particular construal of the self can be described as being socially oriented determinants of happiness.

\section{Purpose of Research}

The main purpose of this paper is to explore how two sets of factors that determine happiness influence two different types of happiness. While it may be possible to describe a culture or a nation by its most prevalent characteristic, every culture is a mix of multifaceted characteristics. Likewise, we argue that it is crucial to pay attention to both types of happiness that exist within one region and to look at the relationship between the two; moreover, the results of our findings have significant implications for public policy that shape and affect citizens' quality of life.

Making generalizations about societies as a whole according to their culture's dominant self-construal overlooks the important detail that each person construes the self in both ways. Kitayama and Markus posit that "the self and the social relations of a given community are mutually constitutive and . . . to 'be well' requires an attunement between the self and social relations that are organized and maintained by the cultural practices and meanings of a community" (2000, p. 114). Furthermore, Lu and Gilmour state that "culture constrains preferences for different types of subjective well-being (individually oriented vs. socially oriented), and thus, prescribes different sources and conditions of subjective well-being for its members" (2004, p. 271). They also note that many socially oriented societies have begun to foster some individually oriented 
values and behaviors more prevalent in Europe and the United States (Lu \& Gilmour, 2004). This suggests a need for research that addresses both orientations of happiness within a single culture. Thus, in this research, we explore both types of happiness within one society-Seoul—in hopes of providing insights that can lead to policy making aimed at improving specific aspects of citizens' well-being.

\section{RESEARCH METHODS AND CONTENTS}

\section{Hypothesis}

We seek to examine the different types of happiness indicators and investigate how these factors influence the two conceptualizations of happiness. Lu and Gilmour (2006), distinguishing between individually oriented and socially oriented subjective well-being, construct a hypothesis that links the type of subjective well-being with the types of self-construal presented by Markus and Kitayama (1991). Specifically, Lu and Gilmour (2006) hypothesized that individually oriented subjective well-being would be strongly correlated with the independent self-construal and that socially oriented subjective well-being would be strongly correlated with the interdependent self-construal. Although our study's independent variables are different from those used in previous research, this line of reasoning provides support for the hypothesis we propose in this research, that demographic factors and environmental factors will have differentiated effects on individually oriented and socially oriented happiness.

We conjecture that depending on the basis of each determinant of happiness, the impact of those determinants is likely to correlate with the type of happiness that they correspond to. In particular, demographic factors, which characterize an individual independent of social interactions, are likely to play a significant role in individually oriented happiness; and environmental factors, which figure largely in evaluations of satisfaction that favor activities involving social interactions, are likely to strongly affect socially oriented happiness. The analytical framework for this hypothesis is illustrated in Figure 1.

Markus and Kitayama suggest that an individual's self-construal splits between the "interdependent self," whereby the self is perceived as "interdependent with the surrounding context," and the "independent self," which emphasizes an autonomous self-representation (1991, p. 225-226). Accordingly, the specific set of attributes associated with a particular self-construal dictates a person's psychological processes, which involves cognition, emotion, and motivation (Markus \& Kitayama, 1991). For instance, individuals who tend to construe themselves in terms of interdependence are 
Figure 1. Analytical Framework for Research

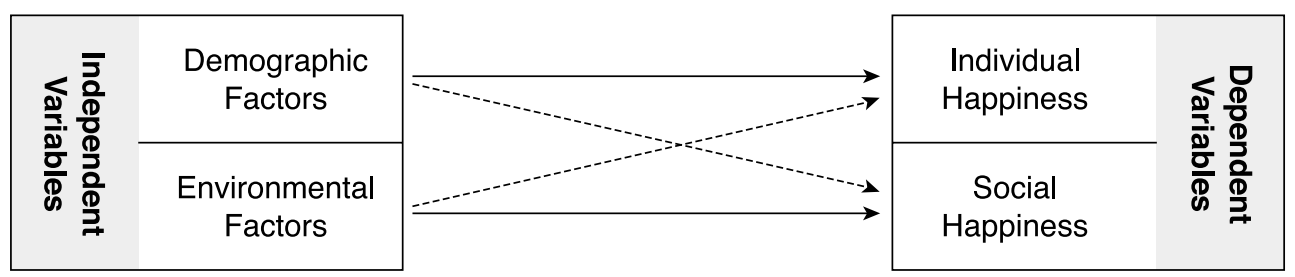

characterized as being "influenced by a pervasive attentiveness to the relevant others in the social context" (Markus \& Kitayama, 1991, p. 225), whereas those who construe themselves in terms of independence view the self as constructed independently of interactions and comparisons with others in a society.

\section{Subject of Research and Data Collection Method}

\section{Seoul Survey: Data of householders}

We used data from the 2012 Seoul Survey to analyze and verify the research hypothesis. Conducted from October 12, 2012, to November 9, 2012, via door-to-door interviews, the 2012 Seoul Survey collected data from 49,758 Seoul citizens over the age of 15 . Of these respondents, 20,000 were heads of household that filled out extra questions pertinent to our research; for this specific reason, we only used data gathered from these respondents. The population sample for this survey was selected using a stratified two-stage cluster sampling method. The data sampling error at the $95 \%$ confidence level was $\pm 0.69 \%$ p in the case of householders and $\pm 0.46 \%$ p in the case of members of household (Seoul, 2013). We applied weights to the data in order to enhance sample representativeness. ${ }^{1}$

\section{Dependent variables}

The dependent variables in this research are individually oriented and socially oriented happiness. The survey question used to measure respondents' happiness asked respondents to self-evaluate their happiness in the following five domains: health status, financial status, relationships, family life, and social life. Of these

1. The 2012 Seoul Survey provides several sets of weights calculated by using different weighting structures. Detailed explanations and mathematical formulas are found in the 2012 Seoul Survey Report (Seoul, 2013, p. 406). 
domains, respondents' self-ratings pertaining to their health and financial status were used for measuring their individually oriented happiness and self-ratings concerning social life (e.g., work, school, religious activities, hobbies, etc.) and relationships with family and friends were used to gauge socially oriented happiness. Responses were coded using a 10-point Likert scale in which state of extreme unhappiness $=0$ and state of extreme happiness $=10 .^{2}$

\section{Independent variables}

No one variable or set of variables can fully explain people's happiness, as happiness is a multifaceted and complex emotion (Diener, 1984). However, numerous years of research of such factors has enabled scholars to identify various determinants that seem to be correlated closely with happiness. Table 1 below shows the operational definitions and measurements of the demographic and environmental factors we chose to draw on for this research.

Table 1. Operational Definitions and Measurements of Factors

\begin{tabular}{|c|c|c|c|}
\hline & Factors & Survey Questions & Measurements \\
\hline \multirow{2}{*}{ 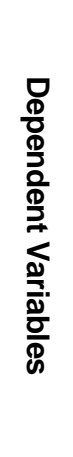 } & $\begin{array}{l}\text { individually } \\
\text { oriented } \\
\text { happiness }\end{array}$ & $\begin{array}{l}\text { Would you say you have been feeling } \\
\text { happy recently? Please indicate your } \\
\text { happiness score for the following } \\
\text { categories: } \\
\text { 1) health status, 2) financial status }\end{array}$ & $\begin{array}{l}\text { extremely happy }=10, \ldots \\
\text { extremely unhappy }=0\end{array}$ \\
\hline & $\begin{array}{c}\text { socially } \\
\text { oriented } \\
\text { happiness }\end{array}$ & $\begin{array}{l}\text { Would you say you have been feeling } \\
\text { happy recently? Please indicate your } \\
\text { happiness score for the following } \\
\text { categories: } \\
\text { 3) relationships with relatives and friends, } \\
\text { 4) family life, 5) social life (work, school, } \\
\text { religious life, hobbies, etc.) }\end{array}$ & $\begin{array}{l}\text { extremely happy }=10, \ldots \\
\text { extremely unhappy }=0\end{array}$ \\
\hline \multirow{4}{*}{ 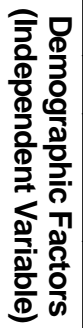 } & gender & respondents' gender & male $=1$, female $=0$ \\
\hline & age & respondents' age & $10 s=1,20 s=2, \ldots 60 s$ or above $=6$ \\
\hline & education & $\begin{array}{l}\text { What is the highest level of education } \\
\text { you have completed? }\end{array}$ & $\begin{array}{l}\text { up to middle school=1, } \\
\text { high school= } 2 \text {, college }=3 \text {, } \\
\text { graduate school or above }=4\end{array}$ \\
\hline & marital status & What is your marital status? & $\begin{array}{l}\text { married }=1, \text { single }=2, \\
\text { divorced } / \text { separated } / \text { bereaved }=3\end{array}$ \\
\hline
\end{tabular}

2. Cronbach alpha coefficient of each dependent variable is as follows: individually oriented happiness $(0.664)$, socially oriented happiness $(0.860)$ 


\begin{tabular}{|c|c|c|c|c|}
\hline & Factors & \multicolumn{2}{|c|}{ Survey Questions } & Measurements \\
\hline \multirow{6}{*}{ 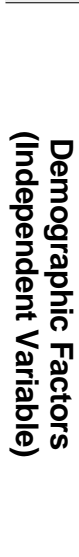 } & religion & \multicolumn{2}{|c|}{ Do you have a religion? } & yes $=1$, no $=0$ \\
\hline & $\begin{array}{l}\text { household } \\
\text { income }\end{array}$ & \multicolumn{2}{|c|}{$\begin{array}{l}\text { What was your average monthly pretax } \\
\text { household income last year (October } 1 \text {, } \\
2010 \text {, to September 30,2011)? }\end{array}$} & $\begin{array}{l}W 1,000,000 \text { or less }=1, \ldots \\
W 5,000,000 \text { or more }=6\end{array}$ \\
\hline & $\begin{array}{l}\text { employment } \\
\text { status }\end{array}$ & \multicolumn{2}{|c|}{ What is your employment status? } & $\begin{array}{l}\text { full-time }=1 \text {, temporary } \\
\text { position }=2 \text {, unemployed }=3\end{array}$ \\
\hline & $\begin{array}{c}\text { type of } \\
\text { occupancy }\end{array}$ & \multicolumn{2}{|c|}{ What is your occupancy status? } & $\begin{array}{l}\text { own home }=1, \text { jeonse } e^{3}=2 \\
\text { monthly rent, etc. }=3\end{array}$ \\
\hline & $\begin{array}{l}\text { occupancy } \\
\text { period }\end{array}$ & \multicolumn{2}{|c|}{$\begin{array}{l}\text { How many years have you lived in } \\
\text { Seoul at your current address? }\end{array}$} & indicate number of years \\
\hline & $\begin{array}{l}\text { residential } \\
\text { region }\end{array}$ & \multicolumn{2}{|c|}{ What region of Seoul do you live in? } & $\begin{array}{l}\text { Gangnam }=1 \text {, } \\
\text { not Gangnam }=0\end{array}$ \\
\hline \multirow{5}{*}{ 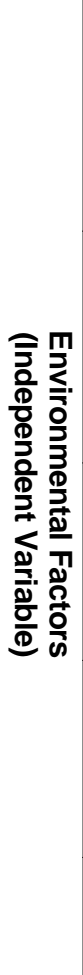 } & transportation & $\begin{array}{l}\text { satisfaction } \\
\text { with } \\
\text { transportation } \\
\text { system }\end{array}$ & $\begin{array}{l}\text { Please indicate your } \\
\text { level of satisfaction with } \\
\text { the bus, subway, taxi } \\
\text { systems and the walking } \\
\text { environment (residential } \\
\text { area and downtown) }\end{array}$ & $\begin{array}{l}\text { very satisfied }=5, \ldots \\
\text { very unsatisfied }=1\end{array}$ \\
\hline & urban safety & $\begin{array}{l}\text { urban safety } \\
\text { level }\end{array}$ & $\begin{array}{l}\text { Please indicate } \\
\text { perceived degree of risk } \\
\text { regarding the following: } \\
\text { natural disasters, walking } \\
\text { at night, crimes, and } \\
\text { construction accidents. }\end{array}$ & $\begin{array}{l}\text { not at all dangerous }=5 \ldots \\
\text { very dangerous }=1\end{array}$ \\
\hline & environment & $\begin{array}{l}\text { satisfaction } \\
\text { with urban } \\
\text { living } \\
\text { environment }\end{array}$ & $\begin{array}{l}\text { How serious do you think } \\
\text { the following problems } \\
\text { are: air or water pollution } \\
\text { and lack of park or green } \\
\text { space }\end{array}$ & $\begin{array}{l}\text { not at all serious }=4 \ldots \\
\text { very serious }=1\end{array}$ \\
\hline & trust & \multicolumn{2}{|c|}{$\begin{array}{l}\text { What is your level of trust regarding the } \\
\text { following: } \\
\text { 1) family, 2) neighbors, 3) someone you } \\
\text { met for the first time, 4) foreigners, and } \\
\text { 5) public organizations }\end{array}$} & $\begin{array}{l}\text { very high level of trust }=5, \ldots \\
\text { very low level of trust }=1\end{array}$ \\
\hline & social status & \multicolumn{2}{|c|}{$\begin{array}{l}\text { Within your society, what is the likelihood } \\
\text { of elevating your social position through } \\
\text { hard work? }\end{array}$} & very high $=5, \ldots$ very low $=1$ \\
\hline
\end{tabular}

3. Jeonse is a form of residential system in South Korea. A resident is required to put down a sizable lump-sum deposit upfront and is not required to pay any additional rent until the end of the lease contract. Contracts usually last for one to three years.

4. Green space includes roadside trees, lawns, gardens, and any green areas in a city. 


\begin{tabular}{|c|c|c|c|}
\hline & Factors & Survey Questions & Measurements \\
\hline \multirow{6}{*}{ 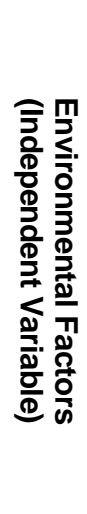 } & culture & $\begin{array}{l}\text { How satisfied are you with the cultural } \\
\text { environment in Seoul? }\end{array}$ & $\begin{array}{l}\text { very satisfied }=5, \ldots \\
\text { very unsatisfied }=1\end{array}$ \\
\hline & \multirow{2}{*}{$\begin{array}{l}\text { group } \\
\text { participation }\end{array}$} & $\begin{array}{l}\text { Have you ever attended any festivals } \\
\text { in Seoul? }\end{array}$ & \multirow{2}{*}{ yes $=1$, no $=0$} \\
\hline & & $\begin{array}{l}\text { Have you ever participated in any group } \\
\text { activities? }\end{array}$ & \\
\hline & \multirow{2}{*}{$\begin{array}{l}\text { individual } \\
\text { participation }\end{array}$} & $\begin{array}{l}\text { Have you ever participated in any } \\
\text { volunteer work? }\end{array}$ & \multirow{2}{*}{ yes $=1$, no $=0$} \\
\hline & & Have you ever given donations? & \\
\hline & $\begin{array}{l}\text { leisure } \\
\text { activity }\end{array}$ & $\begin{array}{l}\text { Do you engage in any leisure activities } \\
\text { on the weekends or on holidays? }\end{array}$ & yes $=1$, no $=0$ \\
\hline
\end{tabular}

\section{Demographic factors}

The demographic factors incorporated in this research are coded as follows. Gender is coded 0 for female and 1 for male, and for age, 1 equals 10s, 2 equals 20s, 3 equals 30s, 4 equals 40s, 5 equals 50s, and 6 equals 60s and above. Education measures respondents' highest level of education completed and is coded 1 for up to middle school, 2 for high school, 3 for bachelor's degree, and 4 for master's degree or higher. For marital status, 0 equals not married (including unmarried, divorced, separated, etc.) and 1 equals married. Religious orientation is coded 0 for not religious and 1 for religious.

\section{Environmental factors}

Level of satisfaction with transportation and urban safety, level of trust, perception of ability to improve social status, and level of involvement in cultural activities are coded using five-point scales; level of satisfaction with the environment is coded using a four-point scale. Group participation, individual participation, and engagement in leisure activities are coded 1 for yes and 0 for no. ${ }^{5}$

5. Cronbach alpha coefficient of each environmental factor is as follows: transportation (0.640), urban safety (0.736), environment (0.610), group participation (0.233), and individual participation (0.400). 


\section{RESEARCH RESULTS}

\section{Descriptive Statistics of Happiness (Dependent Variables)}

The descriptive statistics of happiness are presented in Table 2 below. A total of 20,000 respondents responded to the survey question asking them to indicate their happiness scores on a scale of zero to 10 . For individually oriented happiness, the average is 6.4880 with a standard deviation of 1.3507 . The average for socially oriented happiness is 6.8260 with a standard deviation of 1.2324. Leaning toward seven, the mean happiness scores for both categories of happiness highlight that, for the most part, many respondents are relatively happy. The difference in means of the two factors is not statistically significant.

Table 2. Descriptive Statistics of Happiness

\begin{tabular}{c|c|c|c|c|c}
\hline Factors & $\mathrm{N}$ & Mean & $\mathrm{SD}$ & Min & Max \\
\hline $\begin{array}{c}\text { individually oriented } \\
\text { happiness }\end{array}$ & 20,000 & 6.4880 & 1.3507 & 0 & 10 \\
\hline $\begin{array}{c}\text { socially oriented } \\
\text { happiness }\end{array}$ & 20,000 & 6.8260 & 1.2324 & 0 & 10 \\
\hline
\end{tabular}

\section{Descriptive Statistics of Demographic Factors (Independent Variables)}

The descriptive statistics of the demographic factors are shown in Table 3. Since most householders in South Korea are males, the number of male respondents was much higher than that of female respondents. Also, because a majority of heads of households tends to be older, the age distribution was not spread out evenly; in fact, $93.4 \%$ of respondents were in their 30 s or older, compared to $6.6 \%$ of respondents in their 20 s or younger. Respondents in their 40 s and 50 s constituted $57.7 \%$ of the sample.

The average education level of respondents was quite high with an overwhelming majority - about $90 \%$ - of respondents reporting that they graduated at least from high school. According to the descriptive statistics for monthly household income, $40.1 \%$ of respondents earned over $\$ 4$ million, $25.3 \%$ earned between $\$ 3$ and $\$ 4$ million, and $34.5 \%$ made less than $\mathrm{W} 3$ million. Of the respondents, $82.7 \%$ were employed full-time, while $4.6 \%$ held temporary positions and $12.8 \%$ were unemployed.

For residence type, $41.2 \%$ of respondents owned homes, $32.9 \%$ resided in jeonsetype homes, and the remaining $25.9 \%$ paid monthly rent. In terms for occupancy period, $10.7 \%$ of the respondents indicated that they had been living at their current address 
Table 3. Descriptive Statistics of Demographic Factors

\begin{tabular}{|c|c|c|c|c|c|}
\hline Factors & Category & Freq. (\%) & Factors & Category & Freq. (\%) \\
\hline \multirow{2}{*}{ gender } & male & $15,756(78.8)$ & \multirow{3}{*}{$\begin{array}{l}\text { residence } \\
\text { type }\end{array}$} & own & $8,234(41.2)$ \\
\hline & female & $4,244(21.2)$ & & jeonse & $6,580(32.9)$ \\
\hline \multirow{5}{*}{ age } & 20 s or below & $1,330 \quad(6.6)$ & & monthly rent & $5,186(25.9)$ \\
\hline & $30 \mathrm{~s}$ & $4,301(21.5)$ & \multirow{6}{*}{$\begin{array}{l}\text { occupancy } \\
\text { period }\end{array}$} & 1 year or less & $2,145(10.7)$ \\
\hline & $40 \mathrm{~s}$ & $5,227(26.1)$ & & $1-5$ years & $9,553(47.8)$ \\
\hline & $50 \mathrm{~s}$ & $4,638(23.2)$ & & $5-10$ years & $5,101(25.5)$ \\
\hline & 60 s or above & $4,505(22.5)$ & & $10-15$ years & $1,521 \quad(7.6)$ \\
\hline \multirow{4}{*}{$\begin{array}{l}\text { education } \\
\text { (graduated) }\end{array}$} & middle school $\downarrow$ & $2,122(10.6)$ & & $15-20$ years & $888 \quad(4.4)$ \\
\hline & high school & $6,877(34.3)$ & & 20 years $\uparrow$ & 792 (4.0) \\
\hline & college & $10,633(53.2)$ & \multirow{2}{*}{$\begin{array}{l}\text { residential } \\
\text { region }\end{array}$} & Gangnam & $4,078(20.4)$ \\
\hline & graduate school $\uparrow$ & 368 (1.8) & & other & $15,922(79.6)$ \\
\hline \multirow{3}{*}{$\begin{array}{l}\text { marital } \\
\text { status }\end{array}$} & Single & $5,190(26.0)$ & \multirow{6}{*}{$\begin{array}{l}\text { household } \\
\text { income }\end{array}$} & $1,000,000^{6} \downarrow$ & 780 (3.9) \\
\hline & married & $13,144(65.7)$ & & $\begin{array}{l}1,000,000- \\
2,000,000\end{array}$ & 2,323 (11.6) \\
\hline & divorced, etc. & $1,666 \quad(8.3)$ & & $\begin{array}{l}2,000,000- \\
3,000,000\end{array}$ & $3,804(19.0)$ \\
\hline \multirow{3}{*}{$\begin{array}{l}\text { employment } \\
\text { status }\end{array}$} & full-time & $16,534(82.7)$ & & $\begin{array}{c}3,000,000- \\
4,000,000\end{array}$ & $5,069(25.3)$ \\
\hline & $\begin{array}{l}\text { temporary } \\
\text { position }\end{array}$ & $914 \quad(4.6)$ & & $\begin{array}{l}4,000,000- \\
5,000,000\end{array}$ & $4,009(20.0)$ \\
\hline & unemployed & $2,552(12.8)$ & & $5,000,000 \uparrow$ & $4,016(20.1)$ \\
\hline \multirow{2}{*}{ religion } & Yes & $9,357(46.8)$ & & & \\
\hline & No & 10,643 (53.2) & & & \\
\hline
\end{tabular}

for one year or less, almost half, $47.8 \%$, for one to five years, $25.5 \%$ for five to 10 years, $7.6 \%$ for 10 to 15 years, $4.4 \%$ for 15 to 20 years, and $4.0 \%$ for over 20 years. Well over half, $79.6 \%$ of the respondents, lived in Gangbuk - the area north of the Han river-or other non-Gangnam areas, and $20.4 \%$ of respondents lived in Gangnamthe area south of the river.

6. The monetary unit is the Korean won. $W 1,000,000$ is approximately equivalent to USD $\$ 1,000$. 
Marital status data revealed that $65.7 \%$ of respondents were married, $8.3 \%$ were divorced, separated, or bereaved, and $26 \%$ were unmarried. Regarding religion, $46.8 \%$ reported that they had a religion, while $53.2 \%$ reported that they were not religious.

\section{Descriptive Statistics of Environmental Factors (Independent Variables)}

The descriptive statistics of environmental factors are presented in Table 4-1 and Table 4-2.

The average score for satisfaction with transportation is 3.52 on a five-point scale, revealing that, in general, the degree of satisfaction is above average. The mean score is 3.25 on a five-point scale for the level of urban safety, 2.94 on a four-point scale for the level of environmental safety, and 3.08 on a five-point scale for trust in others or organizations. The scores for all three factors are at or slightly higher than their respective midpoints. Respondents reported that the possibility of elevating one's social position in society through effort is low, with a mean score of 3.03. The average satisfaction level with the cultural environment in Seoul is 3.53, the highest score out of all the factors. This implies that Seoul residents are generally satisfied with cultural institutions or facilities, such as theaters, galleries, and museums.

Table 4-1. Descriptive Statistics of Environmental Factors

\begin{tabular}{c|c|c|c|c|c}
\hline Factors & $\mathrm{N}$ & Mean & $\mathrm{SD}$ & Min & Max \\
\hline transportation & 20,000 & 3.5188 & 0.4836 & 1 & 5 \\
\hline urban safety & 20,000 & 3.2498 & 0.6536 & 1 & 5 \\
\hline environment & 20,000 & 2.9409 & 0.5331 & 1 & 4 \\
\hline trust & 20,000 & 3.0795 & 0.5243 & 1 & 5 \\
\hline social status & 20,000 & 3.0323 & 0.8879 & 1 & 5 \\
\hline culture & 20,000 & 3.5340 & 0.9088 & 1 & 5 \\
\hline
\end{tabular}

Table 4-2. Descriptive Statistics of Environmental Factors

\begin{tabular}{c|c|c|c}
\hline Factors & $\mathrm{N}$ & Yes(=1) Freq.(\%) & $\mathrm{No}(=0)$ Freq.(\%) \\
\hline group participation & 20,000 & $17,380(86.9)$ & $2,620(13.1)$ \\
\hline individual participation & 20,000 & $8,641(43.2)$ & $11,359(56.8)$ \\
\hline leisure activity & 20,000 & $17,713(88.6)$ & $2,287(11.4)$ \\
\hline
\end{tabular}


Table 4-2 shows the frequencies of responses to yes-or-no survey questions. A large majority of respondents, $86.9 \%$, stated that they had participated in some type of group activity (e.g. hiking clubs or regional and hometown associations), while $13.1 \%$ replied that they had not. A smaller percentage, $43.2 \%$ of respondents, reported participating in individual activities, such as donating money to organizations or doing volunteer work, and $56.8 \%$ reported they had not participated in such activities. A large percentage of respondents, $88.6 \%$, also reported taking part in personal leisure activities, such as watching television, reading books, or playing soccer.

\section{ANALYSIS OF FACTORS THAT INFLUENCE INDIVIDUALLY- AND SOCIALLY ORIENTED HAPPINESS}

\section{Correlation Analysis of the Factors}

Our correlation analysis reveal that the relationship between the two types of happiness and most of the influence factors are statistically significant. Analysis results show that most factors are positively correlated with both individually- and socially oriented happiness, with the exception of age (-.228 for individually oriented happiness, -.169 for socially oriented happiness) and monthly rental occupancy status (-.036 for individually oriented happiness, -.052 for socially oriented happiness). Whether positive or negative, most factors are strongly associated with the two types of happiness. In addition, we analyzed the variance inflation factor (VIF) to verify the existence of multicollinearity. The highest VIF value is 3.464 (for the marital status "married"), but the VIF values for all the other independent variables are lower, confirming that the problem of multicollinearity should not be an issue in this analysis.

\section{Multiple Regression Analysis}

According to the results of the multiple regression analysis, the R-squared values for the regression models were 0.247 for individually oriented happiness and 0.215 for socially oriented happiness (Table 5). While these values appear to be relatively low, it bears repeating that many social scientists tend to overstress the R-squared value in explaining the fit of the regression model (Christensen, 2002). We suggest that Rsquared values above 0.2 are sufficient to explain a good fit of the regression model. 
Table 5. Results of Multiple Regression Analysis

\begin{tabular}{|c|c|c|c|c|c|c|c|c|}
\hline \multirow{2}{*}{\multicolumn{3}{|c|}{$\begin{array}{c}\text { Factors } \\
\text { (Independent Variables) }\end{array}$}} & \multicolumn{3}{|c|}{$\begin{array}{c}\text { Individually Oriented } \\
\text { Happiness }\end{array}$} & \multicolumn{3}{|c|}{$\begin{array}{c}\text { Socially Oriented } \\
\text { Happiness }\end{array}$} \\
\hline & & & \multirow{2}{*}{$\frac{\mathrm{B}^{1}}{-.058^{\star * 2}}$} & \multirow{2}{*}{$\begin{array}{l}\text { SE } \\
.027\end{array}$} & \multirow{2}{*}{$\begin{array}{l}\text { Beta } \\
.018\end{array}$} & \multirow{2}{*}{$\frac{\mathrm{B}}{.051^{* \star}}$} & \multirow{2}{*}{$\begin{array}{l}\text { SE } \\
.025\end{array}$} & \multirow{2}{*}{$\begin{array}{r}\text { Beta } \\
.016\end{array}$} \\
\hline \multirow{13}{*}{ 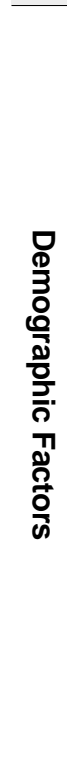 } & \multicolumn{2}{|c|}{ gender } & & & & & & \\
\hline & \multicolumn{2}{|c|}{ age } & $-.108^{\star \star \star}$ & .011 & -.098 & $-.085^{\star \star \star}$ & .010 & -.083 \\
\hline & \multicolumn{2}{|c|}{ education } & $.228^{* * *}$ & .016 & .119 & $.126^{\star \star *}$ & .015 & .072 \\
\hline & \multicolumn{2}{|c|}{ household income } & $.154^{\star \star \star}$ & .008 & .161 & $.142^{\star \star \star}$ & .007 & .161 \\
\hline & \multirow{2}{*}{$\begin{array}{l}\text { employment } \\
\text { status }\end{array}$} & full-time & $.440^{* * *}$ & .029 & .123 & $.205^{\star \star \star}$ & .027 & .062 \\
\hline & & temporary & $.505^{\star \star *}$ & .046 & .078 & $.381^{\star \star \star}$ & .043 & .065 \\
\hline & \multirow{2}{*}{$\begin{array}{l}\text { occupancy } \\
\text { status }\end{array}$} & jeonse & -.011 & .021 & -.004 & $-.051^{\star \star \star}$ & .020 & -.019 \\
\hline & & monthly, etc. & $-.104^{\star \star \star}$ & .027 & -.034 & $-.077^{* * *}$ & .025 & -.025 \\
\hline & \multicolumn{2}{|c|}{ occupancy period } & -.001 & .001 & -.007 & $-.006^{\star * *}$ & .001 & -.035 \\
\hline & \multicolumn{2}{|c|}{ residential region (Gangnam) } & .030 & .021 & .009 & $.053^{\star \star *}$ & .020 & .017 \\
\hline & \multirow{2}{*}{ marital status } & married & $-.322^{\star * \star}$ & .033 & -.112 & $-.136^{\star \star \star}$ & .031 & -.050 \\
\hline & & divorced etc. & $-.455^{\star \star \star}$ & .036 & -.127 & $-.306^{\star \star \star}$ & .034 & -.093 \\
\hline & \multicolumn{2}{|c|}{ religion } & .023 & .017 & .008 & $.098^{\star \star *}$ & .016 & .040 \\
\hline \multirow{9}{*}{ 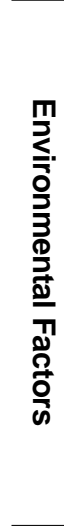 } & \multicolumn{2}{|c|}{ transportation } & $.582^{\star \star \star}$ & .018 & .208 & $.492^{\star \star *}$ & .017 & .182 \\
\hline & \multicolumn{2}{|c|}{ urban safety } & $.031^{* *}$ & .013 & .015 & .001 & .012 & .003 \\
\hline & \multicolumn{2}{|c|}{ environment } & .018 & .016 & .007 & $.043^{\star \star *}$ & .015 & .022 \\
\hline & \multicolumn{2}{|c|}{ trust } & $.193^{* \star *}$ & .016 & .075 & $.156^{\star \star \star}$ & .015 & .068 \\
\hline & \multicolumn{2}{|c|}{ social status } & $.192^{\star \star \star}$ & .010 & .126 & $.172^{\star \star \star}$ & .009 & .123 \\
\hline & \multicolumn{2}{|c|}{ culture } & $.030^{\star \star \star}$ & .009 & .020 & $.029^{\star \star \star}$ & .009 & .021 \\
\hline & \multicolumn{2}{|c|}{ group participation } & $.199^{* * *}$ & .026 & .050 & $.365^{\star \star \star}$ & .024 & .100 \\
\hline & \multicolumn{2}{|c|}{ individual participation } & .019 & .018 & .007 & $.109^{\star \star *}$ & .016 & .044 \\
\hline & \multicolumn{2}{|c|}{ leisure activities } & .037 & .026 & .009 & $.101^{\star \star \star}$ & .024 & .025 \\
\hline & \multicolumn{2}{|c|}{ (constant) } & $1.954^{\star \star *}$ & .116 & - & $2.829^{\star * \star}$ & .108 & - \\
\hline & observed & alues & & & & 000 & & \\
\hline & $\mathrm{R}^{2}$ (adjus & $\left.\mathrm{d} \mathrm{R}^{2}\right)$ & & $17(.24$ & & & $15(.2$ & \\
\hline & F-te & & & 8.158 & & & 9.095 & \\
\hline
\end{tabular}

1. $B=$ Unstandardized Coefficients $B$, Beta $=$ Standardized Coefficients Beta

2. ${ }^{*} p<0.1,{ }^{* *} p<0.05,{ }^{* * *} p<0.01$ 


\section{Individually oriented happiness}

According to the regression analysis (Table 5), a majority of demographic factorswith the exception of jeonse-type occupancy status, occupancy period, residential region, and religion - have statistically significant effects on individually oriented happiness. The standardized coefficient $(\beta)$ values of the following variables are statistically significant and positive in terms of their effects on individually oriented happiness: gender (.180), education (.119), household income (.161), full-time employment status (.123), and temporary employment status (.078).

Gender has the strongest positive influence, and results indicate that men are happier than women. Our results are consistent with Plagnol and Easterlin's (2008) findings that while women's overall happiness is higher in the early stages of adult life, ultimately, men tend to be more satisfied and happier due to their ability to better fulfill life aspirations later in life. However, scholars have not been able to reach a consensus regarding the relationship between gender and happiness (Argyle, 1987; Nolen-Hoeksema \& Rusting, 1999; Plagnol \& Easterlin, 2008). Household income is also highly correlated with individually oriented happiness, and this is generally corroborated by findings from numerous other studies (Diener, Tay, \& Oishi, 2013; Argyle, 1999; Blanchflower \& Oswald 2004; Chen, 2012).

Type of employment can influence various facets of happiness, including positive affect, self-esteem, satisfaction, and health (Argyle, 1999). Accordingly, our regression results reveal that full-time employment has a considerably stronger impact on individually oriented happiness than do temporary jobs and unemployment. This correlation between employment type and individually oriented happiness seems logical against the backdrop of a general tendency to prefer full-time positions to temporary ones or unemployment.

The positive association between education and individually oriented happiness is noteworthy as well. Various scholars have shown that level of education is positively related to happiness (Chen, 2012; Blanchflower \& Oswald, 2004; Easterlin, 2001; Yang, 2008). Scholars argue that education builds people's knowledge and understanding, thereby enhancing their sense of autonomy (Michalos, 2008; Brighouse, 2006; Chen, 2012; Layard, 2005; Yang, 2008). Chen (2012) reports that non-monetary factors (e.g., interpersonal relationships, cosmopolitanism) play critical roles in explaining the education-happiness relationship, and this was observed in the samples from South Korea, Japan, and Taiwan. Hence, education can boost happiness by creating a channel that connects people to various external factors (e.g., social relationships, participation in activities, etc.).

The $\beta$ values of the following factors are statistically significant and negative in 
terms of their effects on individually oriented happiness: age (-.098), monthly rental occupancy status (-.034), married (-.112), and divorced/separated/bereaved (-.127). Of these variables, the two marital status factors had the strongest negative effects on individually oriented happiness. In particular, while both married individuals and those no longer married were unhappy, individuals who were divorced/separated/bereaved were slightly less happy than those who were married.

Numerous studies report that individuals' happiness increases with age (Cantril, 1965; Argyle, 1999; Carstensen, Pasupathi, Mayr, \& Nesselroade, 2000; Lacey, Smith, \& Ubel, 2006). For example, the U-bend of life explains that people are generally content in the early stages of adult life, experience a sharp decline in life satisfaction during middle age, and then become happier again as they age (Economist, 2010; Chen, 2012; Gertham \& Johannesson, 2001; Yang, 2008; Blanchflower \& Oswald, 2008). In sharp contrast, our analysis results reveal a negative relationship between age and individually oriented happiness. As Jung (2013) explains, this negative effect that age has on the happiness of Seoul citizens is primarily due to the lack of adequate elderly welfare crucial for maintaining minimum living standards. Korea's considerably high poverty rate (i.e., $45.1 \%$ during the mid-2000s) (OECD, 2013) and suicide rate (72\% in 2010) (OECD, 2014) among those over 65 reinforce Jung's argument and support our analysis results.

Though renting month by month shows a statistically significant, albeit comparatively weaker, relationship to both types of happiness, jeonse-type occupancy status (-.019) turned out to be only correlated with socially oriented happiness. This may be due to the prevalent social belief that equates home ownership with great personal achievement. Occupancy period (-.035), residential region (.017), and religion (.040) also only impact socially oriented happiness. Ferris (2002) explains that the relationship between religion and happiness is statistically significant and positive. The positive connection between religion and socially oriented happiness suggests that building social relationships with others within one's religious group is a consequence of being religious and taking part in religious events. Thus, while having a religion may not affect personal happiness, it positively influences socially oriented happiness.

\section{Socially oriented happiness}

We find that environmental factors, overall, more strongly influence socially oriented happiness; although the difference is fairly minimal, satisfaction with transportation, ability to trust others, and a belief that one can improve one's social status through work are exceptions, as they are slightly more associated with individually oriented happiness. With the exception of perception of the level of urban safety, all environ- 
mental factors have statistically significant and positive effects on socially oriented happiness: transportation (.182), urban living environment (.022), trust (.068), social status (.123), culture (.021), group participation (.100), individual participation (.044), and leisure activity (.025). Of these variables, transportation has the strongest relationship with socially oriented happiness.

Because transportation services and facilities are a major aspect of communities, it is not surprising to see that satisfaction with transportation systems has the strongest connection with both levels of happiness. The type and quality of transportation impacts the travel experience, thereby affecting the traveler's behavior and happiness (Duarte, Garcia, Giannarakis, Limão, Polydoropoulou, \& Litinas, 2010). Ability to trust others and the belief that one can move up the social ladder if one works hard both have somewhat stronger impacts on socially oriented happiness. Various studies report that being able to trust others is a statistically significant factor of happiness (Kuroki, 2011; Bălţătescu, 2002; Nye, 1997; Braud, 1997). Regarding social status, it is intriguing to observe that this factor was more strongly, although only very slightly, related to individually oriented happiness, given that it is directly related to an individual's relationships with various aspects of his or her society.

Group participation has a stronger impact on socially oriented happiness (.100) than on individually oriented happiness (.050). This positive correlation is consistent with Phillips's (1967) findings that engaging in social activities increases happiness due to direct association between positive emotions and social participation. On the other hand, individual participation only has a minor impact on socially oriented happiness. We speculate that in Asian societies, which are characterized by collective culture (Lu \& Gilmour, 2006), even individual participation is considered a social act; specifically, when, for example, an individual makes a donation to an organization, as opposed to feeling a sense of personal accomplishment, the individual tends to feel that he or she has fulfilled a social obligation.

Furthermore, culture (i.e., satisfaction with the cultural environment) and leisure activities (i.e., engagement in such activities) are positively correlated with socially oriented happiness. Because cultural and leisure activities promote interactions and cultivate a sense of belonging, these variables are likely to have effects on social happiness. Many studies support the positive correlation between leisure and happiness (Lloyd \& Auld 2002; Nawjin \& Veenhoven, 2011; Baldwin \& Tinsley, 1988; Dowall, Bolter, Flett, \& Kammann, 1988; Wankel \& Berger, 1990). Unlike cultural environment, leisure activities did not affect individually oriented happiness. Because many Seoul citizens engage in leisure activities that involve others (e.g., going to cafes, the theater, or on group vacations), partaking in leisure activities is likely to have more of an effect on socially oriented happiness. 
As expected, environment has a significant impact on socially oriented happiness but not on individually oriented happiness. Aspects of the environment that were addressed in the survey were features that affect society as a whole (e.g., parks, pollution). Perceptions regarding the level of urban safety have a statistically significant effect on individually oriented happiness (.015) but no effect on socially oriented happiness. We infer that many people tend to perceive dangers to safety (e.g., crime, accidents) on a personal rather than social level.

\section{Discussion}

As expected, the regression analysis reveals general patterns in which demographic factors are more strongly correlated with individually oriented happiness and environmental factors with socially oriented happiness. When comparing the standardized coefficient $(\beta)$ values of the statistically significant demographic factors, we notice that these variables affect individually oriented happiness more than socially oriented happiness. On the other hand, when only looking at the $\beta$ values, we see that environmental factors do not consistently have stronger effects on socially oriented happiness than on individually oriented happiness. Nevertheless, when considering that eight environmental factors are associated with socially oriented happiness, as opposed to six factors with individually oriented happiness, and that the differences between each factor's $\beta$ values for the two types of happiness are minimal, environmental factors do, indeed, appear to be more strongly linked with socially oriented happiness than with individually oriented happiness.

Consequently, we conclude that the results of our multiple regression analysis support our hypothesis. Specifically, increases in happiness as a consequence of demographic factors are more closely related to individually oriented- rather than socially oriented happiness. Similarly, environmental factors tend to more strongly influence socially oriented happiness. Furthermore, the analysis results also support our postulation that each class of factors will influence the corresponding as well as the noncorresponding types of happiness, indicating that the factors affect overall happiness. This conclusion is consistent with previous research findings that verify the association between determinants of happiness and people's general sense of happiness and subjective well-being. 


\section{CONCLUSION}

This research centers on identifying specific types of influence factors-demographic and environmental — and comparing their effects on people's individually oriented- and socially oriented happiness. Differentiating between the two conceptualizations of happiness enabled us not only to look at the factors' impact on overall happiness but also to analyze how each type of factor interacts with each type of happiness, allowing us to observe which factors have statistically significant impacts on each of the kinds of happiness.

We conducted a multiple regression analysis to verify our hypothesis, which postulated that demographic and environmental factors would affect the two types of happiness differently. The demographic factors in this research are closely associated with an individualistic perception of the self, while the environmental factors are based on a collective perception of the self. Hence, demographic factors are more likely to be highly correlated with individually oriented happiness and environmental factors with socially oriented happiness. The results of this analysis support our hypothesis. Moreover, although each class of factors has stronger statistically significant influences on the corresponding conceptualization of happiness, both are closely related to each type of happiness. This finding is consistent with results of other studies that have looked at the impact of these factors on overall happiness.

This study has several important implications. From an academic standpoint, it illustrates the significance of distinguishing between two types of happiness. By so doing, our research overcomes an important limitation in previous studies that rely on a general definition of happiness, suggesting a more specific way to conceptualize happiness. Our research findings reveal that influence factors have varying impacts on the two types of happiness and this, in turn, reveals important information about what makes Seoul citizens happy. Specifically, relationships between certain factors and happiness may be counterintuitive. For instance, participation in activities deemed to be nonsocial was only correlated with socially oriented happiness. Although individual participation is an environmental factor, it was surprising to see that individual-level experiences, such as donating money, only affected individuals' socially oriented happiness.

From a practical perspective, results of our research imply that policy makers should be more attentive to the types and effects of policy instruments utilized during the policy-making process. Specifically, legislators should take a more in-depth look at the relationship between policies designed to raise happiness and citizens' actual perception of happiness. In order to do so, legislators must first closely examine which factors are significant indicators of happiness and well-being. Furthermore, by under- 
standing the factors' differentiated effects on individually- and socially oriented happiness, legislators will be able to make more appropriate predictions about how a policy will pan out. By doing so, legislators can develop and execute policies aimed at enhancing societal and national happiness and that minimize the chances of wasting resources.

A limitation of this research is that because the sample used was composed of heads of household, the respondents were primarily males in their thirties or older. Despite the application of weights to remedy this problem and increase the sample's representativeness, the data may be vulnerable to bias in terms of gender and age. Secondly, subsequent research is necessary for the purposes of investigating further types of factors that influence happiness and exploring the correlations in more detail; possible indicators may include political factors and psychological factors. The importance of this research lies in that it takes the first step toward analyzing the relationship between happiness and its correlates from a new perspective. Lastly, future research should carefully examine variables that exhibit the biggest difference in their impacts on the two types of happiness. While this research only compared the effects of different factors, subsequent research should go further and identify more diverse types of variables. The realization of such research will be greatly beneficial to policy makers around the globe.

Policy makers are by and large preoccupied with improving social and collective happiness and thus often fail to appreciate the importance of increasing individually oriented happiness. As findings from our research reveal, influence factors have varying effects on the two types of happiness, indicating that different policy instruments are likely to produce different results. Consequently, policy makers must be more thorough and cautious during the policy-making process and realize that policies designed to increase citizens' happiness should keep people's personal, individualistic happiness in mind as well.

\section{REFERENCES}

Ahuvia, A. 2002. Individualism/collectivism and cultures of happiness: A theoretical conjecture on the relationship between consumption, culture and subjective well-being at the national level. Journal of Happiness Studies, 3(1): 23-36.

Argyle, M. 1999. Causes and correlates of happiness. In D. Kahneman, E. Diener, \& N. Schwarz (eds.), Well-being: The foundations of hedonic psychology (pp. 353-373). New York: Russell Sage Foundation.

Bălţătescu, S. 2002. Trust in institutions and well-being: A state of the art. Analele 
Universităţii din Oradea, Fascicula Sociologie-Filosofie-Asistenţă Socială, 1(1): 95-99.

Baldwin, K., \& Tinsley, H. 1988. An investigation of the validity of Tinsley and Tinsley's (1986) theory of leisure experience. Journal of Counseling Psychology, 35(3): 263-267.

Blanchflower, D. G., \& Oswald, A. J. 2004. Well-being over time in Britain and the USA. Journal of Public Economics, 8(1): 1359-1386.

Braud, P. 1997. Decline of the founding values of democracy and weakening of quasimissionary institutions. Studies in Comparative International Development, 32(3): 112-123.

Brighouse, H. 2006. On Education. New York: Routledge.

Cantril, H. 1965. The Pattern of Human Concerns. New Jersey: Rutgers University Press.

Carstensen, L. L., Pasupathi, M., Mayr, U., \& Nesselroade, J. R. 2000. Emotional experience in everyday life across the adult life span. Journal of Personality and Social Psychology, 79(4): 644-655.

Chen, W. 2012. How education enhances happiness: Comparison of mediating factors in four East Asian countries. Social Indicators Research, 106(1): 117-131.

Choi, M. 2011. An analysis of the factors influencing Busan metropolitan city residents' happiness. Korean Journal of Local Government Studies, 15(1): 277-297.

Christensen, R. 2002. Plane answers to complex questions: The theory of linear models. 3rd ed. New York: Springer-Verlag.

Diener, E. 1984. Subjective well-being. Psychological Bulletin, 95(3): 542-575.

Diener, E., Tay, L., \& Oishi, S. 2013. Rising income and the subjective well-being of nations. Journal of Personality and Social Psychology, 104(2): 267-276.

Dowall, J., Bolter, C., Flett, R., \& Kammann, R. 1988. Psychological well-being and its relationship to fitness and activity levels. Journal of Human Movement Studies, 14(1): 39-45.

Duarte, A., Garcia, C., Giannarakis, G., Limão, S., Polydoropoulou, A. \& Litinas, N. 2010. New approaches in transportation planning: Happiness and transport economics. Netnomics, 11(1): 5-32.

Duncan, G. 2008. Should happiness-maximization be the goal of government? Journal of Happiness Studies, 11(2): 163-178.

Easterlin, R. 2001. Income and happiness: Towards a unified theory. Economic Journal, 111(473): 465-484.

Economist. 2010. Age and happiness: The U-bend of life. Retrieved on May 12, 2013, from www.economist.com/node/17722567.

Feather, N. T. 1986. Value systems across cultures: Australia and China. International 
Journal of Psychology, 21(1): 697-715.

Ferris, A. 2002. Religion and the quality of life. Journal of Happiness Studies, 3(3): 199-215.

Flavin, P., \& Keane, M. 2012. Life satisfaction and political participation: Evidence from the United States. Journal of Happiness Studies, 13(1): 63-78.

Freedman, J. 1978. Happy people: What happiness is, who has it, and why. New York: Harcourt Brace Jovanovich.

$\mathrm{Hu}, \mathrm{A}$. 2014. The changing happiness-enhancing effect of a college degree under higher education expansion: Evidence from China. Journal of Happiness Studies, April 23, 1-17. DOI: 10.1007/s10902-014-9528-1.

Jung, K. 2013. Where are we headed? Seoul: Cheong-Rim.

Kitayama, S., \& Markus, H. 2000. The pursuit of happiness and the realization of sympathy: Cultural patterns of self, social relations, and well-being. In E. Diener $\&$ E. Suh (eds.), Culture and subjective well-being (pp. 113-161). Cambridge, MA: MIT Press.

Kondo, D. 1990. Crafting Selves: Power, Gender, and Discourses of Identity in a Japanese Workplace. Chicago: University of Chicago Press.

Kuroki, M. 2011. Does social trust increase individual happiness in Japan? Japanese Economic Review, 62(4): 444-459.

Lacey, H. P., Smith, D. M., \& Ubel, P. A. 2006. Hope I die before I get old: Mispredicting happiness across the adult lifespan. Journal of Happiness Studies, 7(2): $167-182$

Layard, R. 2005. Happiness: Lessons from a new science. London and New York: Penguin Press.

Lee, J. 2014. A study of the determinants of citizen participation in Seoul village community projects with a focus on policy literacy. Korean Journal of Local Government Studies, 17(4): 1-29.

Leyden, K. M., Goldberg, A. \& Michelbach, P. 2011. Understanding the pursuit of happiness in ten major cities. Urban Affairs Review, 47(6): 861-888.

Lim, G. 2012. Recognition of local residents on quality of life and its influencing factors of local residents: focoused on the cities and counties in Gangwon Province. Korean Public Administration and Policy Review, 10(1): 47-89.

Lloyd, K., \& Auld, C. J. 2002. The role of leisure in determining quality of life: Issues of content and measurement. Social Indicators Research, 57(1): 43-71.

Lu, L., \& Gilmour, R. 2004. Culture and conceptions of happiness: Individual oriented and Social oriented SWB. Journal of Happiness Studies, 5(3): 269-291.

Lu, L., \& Gilmour, R. 2006. Individual-oriented and socially oriented cultural conceptions of subjective well-being: Conceptual analysis and scale development. Asian 
Journal of Social Psychology, 9(1): 36-49.

Lu, L., Kao, S., Chang, T., Wu, H., Jin, Z. 2008. The individual- and social-oriented Chinese bicultural self: A subcultural analysis contrasting mainland Chinese and Taiwanese. Social Behavior and Personality, 36(3): 337-346.

Markus, H., \& Kitayama, S. 1991. Culture and the self: implications for cognition, emotion, and motivation. Psychological Review, 98(2): 224-253.

Markus, H. \& Kitayama, S. 1998. The cultural psychology of personality. Journal of Cross-Cultural Psychology, 29(1): 63-87.

Michalos, A. C. 2008. Education, happiness and wellbeing. Social Indicators Research, 87(3): 347-366.

Nawjin, J., \& Veenhoven, R. 2011. The effect of leisure activities on life satisfaction: The importance of holiday trips. In I. Brdar (ed.), The human pursuit of wellbeing: A cultural approach (pp. 39-53). Dordrecht: Springer.

Nolen-Hoeksema, S., \& Rusting, C.L. 1999. Gender differences in well-being. In D. Kahneman, E. Diener, \& N. Schwarz (eds.), Well-being: The foundations of hedonic psychology (pp. 330-350). New York: Russell Sage Foundation.

Nye, J.S., Jr. 1997. The media and declining confidence in government. International Journal of Press/Politics, 2(1): 4-9.

OECD. 2013. Getting older, getting poorer. In OECD Factbook 2013: Economic, Environmental and Social Statistics. Paris: OECD Publishing.

OECD. 2014. OECD Economic Surveys: Korea 2014. Paris: OECD Publishing.

Phillips, D. 1967. Social participation and happiness. American Journal of Sociology, 72(5): 479-488.

Phillips, D. 1969. Social class, social participation, and happiness: A consideration of “interaction-opportunities” and “investment.” Sociological Quarterly, 10(1): 3-21.

Plagnol, A. C., \& Easterlin, R. A. 2008. Aspirations, Attainments, and Satisfaction: Life Cycle Differences between American Women and Men. Journal of Happiness Studies, 9(4): 601-619.

Rego, A., \& Cunha, M. 2009. How individualism-collectivism orientations predict happiness in a collectivistic context. Journal of Happiness Studies, 10(1): 19-35.

Ryan, R., \& Deci, E. 2001. On happiness and human potentials: A review of research on hedonic and eudemonic well-being. Annual Review of Psychology, 52(1): 141-166.

Seoul. 2013. 2012 Seoul survey. Seoul: Department of Administration.

Veenhoven, R. 1993. Happiness in nations: Subjective appreciation of life in 56 nations, 1946-1992. Rotterdam: Erasmus University of Rotterdam.

Veenhoven, R. 2007. Measures of gross national happiness. Paris: OECD Publishing.

Wankel, L., \& Berger, B. 1990. The psychological and social benefits of sport and 
physical activity. Journal of Leisure Research, 22(2): 167-182.

Waterman, A. S., Schwartz, S. J., \& Conti, R. 2008. The implications of two conceptions of happiness (hedonic enjoyment and eudemonia) for the understanding of intrinsic motivation. Journal of Happiness Studies, 9(1): 41-79.

Woo, Changbin. 2013. Investigating contextual determinants of happiness among Seoul residents. Korean Journal of Policy Studies, 28(2): 49-79.

Yang, A., Hsee, C., \& Zheng, X. 2012. The AB identification survey: Identifying absolute versus relative determinants of happiness. Journal of Happiness Studies, 13(4): 729-744.

Yang, Y. 2008. Social inequalities in happiness in the United States, 1972 to 2004: An age-period-cohort analysis. American Sociological Review, 73(2): 204-226. 